
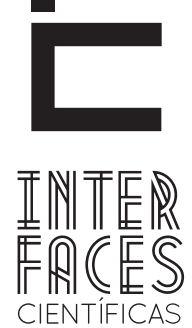

DIREITO

ISSN IMPRESSO 2316-3321

ISSN ELETRÔNICO 2316-381X

DOI 10.17564/2316-381X.2015v3n3p47-56

\title{
MOVIMENTOS SOCIAIS EM REDE: O PAPEL DOS ATORES POLIITICOS E SOCIAIS NA EFETIVAÇ̃̃O DA CIDADANIA BRASILEIRA
}

Aline Antunes Gomes ${ }^{1}$
Luciano de Almeida Lima

\section{RESUMO}

0 advento das novas tecnologias de comunicação e informação propiciou uma abertura do espaço público tradicional, incitando a participação cidadã e as lutas sociais em prol da efetivação dos direitos humanos e fundamentais. Assim, nesse contexto, a pesquisa tem o objetivo de analisar o papel dos novos atores políticos e sociais que emergiram a partir das redes e representam uma resistência aos poderes institucionais tradicionais. Para isso, será utilizado como método de abordagem o hipotético-dedutivo e como métodos de procedimentos o bibliográfico e o histórico.

\section{PALAVRAS-CHAVE}

Cidadania. Movimentos Sociais. Internet. 


\section{ABSTRACT}

The advent of new technologies of communication and information led to greater openness of the traditional public space, encouraging citizen participation and social struggles for realization of human and fundamental rights. Thus, in this context, the research aims to examine the role of new political and social actors that emerged from the networks and represent a resistance to traditional institutional powers. For this, will be used as the hypothetical-deductive method of approach and methods as procedures bibliographic and historical.

\section{KEYWORDS}

Citizenship. Social Movements. Internet.

\section{RESUMEN}

El adviento e las nuevas tecnologías de la comunicación y la información llevó a una mayor apertura del espacio público tradicional, fomentando la participación ciudadana y las luchas sociales para la realización de los derechos humanos y fundamentales. Por lo tanto, en este contexto, la investigación tiene como objetivo examinar el papel de los nuevos actores políticos y sociales que surgieron de las redes y repre-

sentan una resistencia a los poderes institucionales tradicionales. Para ello, se utilizará como el método hipotético-deductivo de enfoque y los métodos como los procedimientos bibliográfico e histórico.

\section{PALABRAS CLAVE}

Ciudadanía; Los movimientos sociales; Internet. 


\section{INTRODUÇ̄̃O}

0 aumento das interconexões em rede alterou 0 processo de comunicação entre os indivíduos, possibilitando que além da disseminação das informações, fosse possível produzi-las e emitir conteúdo. As novas mídias, como blogs e redes sociais, também, propiciaram uma mudança nesse contexto da comunicação, especialmente porque incitaram a formação de um novo espaço público aberto, alterando a relação da sociedade com o estado, que precisou se adaptar e propiciar instrumentos efetivos de participação aos novos cidadãos que estavam e estão surgindo em razão desse meio.

É importante discutir como os movimentos sociais em rede podem contribuir para a efetivação da cidadania e para (re)pensar o papel do Estado Democrático de Direito frente a esses movimentos, pois é a partir das lutas sociais movidas pelos novos atores políticos e sociais que delas emergem que é possível estabelecer um poder de resistência frente ao controle exercido pelas forças institucionais tradicionais.

A luta pela liberdade, por melhores condições de vida e pela proteção do meio em que vivemos, deve constituir elementos constantes nas agendas políticas atuais. Para isso, é preciso mobilizar a sociedade em prol desses direitos, retirá-los da zona de apatia política para realocá-los dentro do ativismo desenvolvido na rede e fora dela. Só assim será possível se pensar em uma real democracia ou na garantia dos direitos de cidadania para todos.

Esta pesquisa, portanto, justifica-se em razão do contexto em que o Brasil e os demais países estão vivendo no que diz respeito aos movimentos sociais e políticos dos cidadãos, que estão potencializando os espaços da internet como palco de suas manifestações.

A mobilização ocorrida a partir de 2004, com a primavera árabe, possibilitou uma abertura global em prol da democracia e dos direitos humanos e acendeu um fio de esperança que move os cidadãos a lutar por seus direitos e fazer frente ao poder de repressão exercido pelo Estado. $E$ as redes somente facilitaram a atuação das massas nesses movimentos, que continua saindo às ruas para protestar por melhores condições de vida, como é o caso das manifestações ocorridas no país em junho de 2013, em razão do preço das passagens de ônibus, e também das manifestações que estão ocorrendo agora em 2015 (fevereiro e março) em virtude do preço do diesel.

\section{MÉTODO}

Trata-se de uma pesquisa qualitativa, em que o método de abordagem utilizado é o hipotético dedutivo, pois o trabalho será desenvolvido a partir da análise de uma hipótese, que questiona se a internet possibilita uma nova forma de exercício da cidadania, para que, com isso, seja possível esboçar uma conclusão acerca do tema. 0 método hipotético-dedutivo foi criado por Karl Popper, a partir do critério da não refutabilidade ou da falseabilidade. Conforme esse critério, uma teoria mantém-se como verdadeira até que seja refutada, ou seja, até que seja mostrada sua falsidade ou seus limites e brechas.

Para Lakatos e Marconi (2001, p. 106), esse método tem início a partir da percepção de uma lacuna nos conhecimentos, "acerca da qual formulam-se hipóteses e, pelo processo de inferências dedutivas, testa-se a predição da ocorrência de fenômenos abrangidos pela hipótese".

A pesquisa bibliográfica é aquela que tem a finalidade de "conhecer as diferentes formas de contribuição científica que se realizaram sobre determinado assunto ou fenômeno" (OLIVEIRA, 1997, p. 119). Assim, os métodos de procedimentos utilizados na pesquisa são o bibliográfico e o histórico, tendo em vista que será realizada uma análise de diversas referências bibliográficas acerca do tema para, então, ser elaborado um 
desenvolvimento e uma conclusão do trabalho. Além disso, o tema possibilita traçar uma linha histórica acerca da evolução do conceito de cidadania e também dos movimentos sociais, tanto dos tradicionais quanto dos desenvolvidos a partir da rede.

\section{DISCUSSÃO E ESTUDO TEÓRICO}

A cidadania tem assumido, ao longo da história, várias formas, em função dos diversos contextos culturais. 0 monoteísmo ético, que é base das grandes religiões ocidentais (cristianismo, islamismo e judaísmo) e encontrou sua expressão no período da decadência da monarquia com a separação nos reinos de Judá, ao sul, e Israel, ao norte, foi provavelmente a primeira expressão documentada e politicamente relevante da cidadania. Em razão disso, pode ser considerada a pré-história da cidadania (PINSKY, 2003, p. 16-17).

No período da antiguidade, a primeira tentativa de desenvolver uma teoria sistemática acerca do assunto foi de Aristóteles, na obra Política. Para esse autor, um cidadão integral era aquele definido "pelo direito de administrar a justiça e exercer funções públicas”, aquele que partilhava dos privilégios da cidade (ARISTÓTELES, 1985, p.1275-1278).

A cidadania, nesse sentido, era o grande objetivo do ateniense, pois, "além de lhe assegurar a participação afetiva na vida pública, garantia-lhe direitos" (ZEIFERT, 2004, p.73). Contudo, tratava-se de uma cidadania limitada, que foi criada em meio a um processo de exclusão, pois somente uma parcela da população poderia participar do governo. As mulheres, os escravos e os estrangeiros não detinham esse direito (KARNAL, 2003, p.143-144).

No sentido moderno, a cidadania é um conceito derivado da Revolução Francesa (1789), mas que também recebeu contribuições da Revolução Inglesa, da Revolução Americana e da Revolução industrial, possuindo como base os princípios da universalidade e igualdade. Para Schnapper (1998, p. 92), a cidadania na sociedade moderna é "ao mesmo tempo o princípio da legitimidade política e a fonte do vínculo social. Viver em conjunto é ser-se conjuntamente cidadão." Isso porque a sociedade democrática visa um projeto de inclusão universal de todos os cidadãos.

No contexto das democracias liberais e parlamentares, a cidadania é muitas vezes empregada como "sinônimo de formas de participação dos indivíduos na vida pública em termos sociais e políticos, outras vezes como sinônimo de civismo, às vezes como sinônimo de civilidade" (PATROCÍNIO, 2008, p. 49), tendo em vista que as formas de vida pública não se restringem apenas aos envolvimentos políticos ou ao exercício do direito de voto. 0 cidadão visa, também, uma fiscalidade do Estado, o uso consciente dos serviços públicos, da segurança social, uma análise do comportamento em relação à lei e à polícia, ao ambiente natural (MADEC; MURARD, 1998, p. 86).

E essas diferentes formas de exercício da cidadania são possíveis, especialmente, pela concepção do espaço público enquanto espaço aberto e flexível, que permite a interação de todos os indivíduos. Para Habermas (1997, p. 92), a esfera ou espaço público:

[...] é um fenômeno social elementar do mesmo modo que a ação, o ator, o grupo ou a coletividade; porém, ele não é arrolado entre os conceitos tradicionais elaborados para descrever a ordem social. A esfera pública não pode ser entendida como uma instituição, nem como uma organização, pois ela constitui uma estrutura normativa capaz de diferenciar entre competências e papéis, nem regula o modo de pertença a uma organização, etc. Tampouco ela constitui um sistema, pois mesmo que seja possível delinear seus limites internos, exteriormente ela se caracteriza através de horizontes abertos, permeáveis e deslocáveis. A esfera pública pode ser descrita como uma rede adequada para a comunicação de conteúdos, tomadas de posição e opiniões; nela os fluxos comunicativos são filtrados e sintetizados, a ponto de se condensarem em opiniões públicas enfeixadas em temas específicos.

Assim, a esfera pública tem como uma das suas 
principais características, ser um espaço irrestrito de comunicação e deliberação pública, que, em princípio, está aberta para todo âmbito social (LUBENOW, 2010, p. 238). E é em razão dessa abertura, do intenso fluxo de comunicações e do processo de inclusão de todos, que os movimentos sociais ganharam força no país, especialmente nas últimas décadas.

De acordo com a historiografia tradicional, os movimentos e lutas sociais ocorridos no Brasil entre 1800-1850 constituem eventos importantes para a construção da cidadania sociopolítica do país. Caracterizavam-se como atos revolucionários, eis que eram motins caóticos e sem um projeto definido. $\mathrm{Na}$ maioria das vezes giravam em torno da construção de espaços nacionais, das legislações, do mercado de trabalho e do poder político, em razão do sistema privilegiado da época.

Destaca-se, desse período, a Revolta dos escravos na Bahia (1807), a Revolução Pernambucana (1817), a Proclamação da Independência (1822), o Movimento Cabanagem, no Pará (1835) e a Guerra dos Farrapos, no Rio Grande do Sul (1835-45) (GOHN, 2001, p. 22-38).

A segunda metade do século XIX foi marcada, principalmente, pelos movimentos em prol dos escravos, como o movimento dos Caifazes, em São Paulo. Já no início do século XX, no período de 1900 a 1930, as lutas sociais ficaram centradas nas questões relacionadas aos trabalhadores imigrantes, que sofriam com políticas e leis restritivas. É também nesse período que o anarco-sindicalismo vive sua fase de auge, com a criação de vários sindicatos de categorias.

Já no período de 1930 a 1945, a luta social adquire novos contornos. "As classes populares começam a emergir como atores históricos sob novos prismas. Paulatinamente vão deixando de ser casos de polícia e se transformando em cidadãos com alguns direitos, como os trabalhistas". Ressalta-se dessa fase, a marcha da fome, em 1931, a Revolução Constitucionalista de 1932, o movimento pelo congelamento dos aluguéis em 1942 e o movimento de associações de bairros, também de 1942 (GOHN, 2001, p. 61-90).

No período denominado populista, que vai de 1945 até 1964, as reinvindicações das lutas sociais eram, principalmente, pelas reformas de base, políticas nacionalistas e equipamentos urbanos para a sobrevivência do grande número de pessoas que se deslocava do campo para a cidade. A fase posterior, que vai de 1964-1974 foi marcada pelos movimentos de resistência ao regime militar instaurado no país e a eclosão do movimento de esquerda, que firmava seus objetivos com base, especialmente, nas Revoluções Russa, Cubana e Chinesa e contava com a formação de vários grupos que surgiram em prol dessa luta, como a Ação Libertadora Nacional (ANL) e a Ação Popular (GOHN, 2001, p. 90-104).

A partir da década de 1980, e especialmente após o fim da ditadura militar, os objetivos das lutas sociais começaram a diversificar-se, formando os novos movimentos sociais, que traziam como base a reivindicação pelos direitos das mulheres, a proteção ao meio ambiente, contra a proliferação nuclear, expansão dos direitos civis, entre outros. Para Jorge Alberto Machado (2007, p. 254),

\begin{abstract}
A mudança no entendimento da organização e ação dos coletivos sociais ocorreu, em grande parte, em decorrência das transformações no cenário político internacional. Com o fim da guerra fria e o surgimento da simbiose entre democracia ocidental e capitalismo, os movimentos sociais passaram gradualmente a ser considerados atores sociais importantes para a promoção dos direitos civis e da cidadania.
\end{abstract}

As iniciativas da sociedade civil passaram a ser vistas como manifestações próprias, típicas e adequadas para um ambiente social plural e não mais como subversivas, revolucionárias ou marginais (MACHADO, 2007, p. 255). O papel dos movimentos passou a ser de catalisador de demandas sociais não contempladas pelo estado e coube aos cidadãos efetivar ações conjuntas em prol de uma sociedade mais justa e igualitária. 
E esse papel dos movimentos foi fortalecido com o advento das novas tecnologias de comunicação e informação, que atuam como recursos capazes de fortalecer o processo democrático, tendo em vista as diferentes formas de interlocução que ocorrem na internet, desde a troca de e-mails numa base cidadão-cidadão, chats e grupos de discussão até amplas conferências (MAIA, 2008, p.277).

A internet se tornou um sistema de comunicação essencial para encontrar pessoas e grupos que partilham dos mesmos valores, porque ela não possui uma limitação territorial ou cultural; pelo contrário, abarca os diferentes modos próprios de vida e sentido (CASTELLS, 2003, p. 170).

Além disso, a diversidade de pessoas, lugares e culturas que são aproximadas pelas redes possibilitam que os movimentos sociais passem da defesa de um sujeito identitário único para a defesa de um sujeito plural. Há uma identificação do sujeito com diversas causas, porque ele não se assume com uma única identidade e isso facilita a inserção em diversos contextos. É o caso, por exemplo, da luta das mulheres pelo feminismo e racismo. 0 movimento feminino possibilitou que as questões raciais fossem trabalhadas conjuntamente, especialmente pela discriminação sofrida pelas mulheres negras.

Contudo, essa concepção de sujeito plural só se fortaleceu com o advento da Web 2.0, que determinou a passagem de uma mídia alternativa para uma mídia participativa, isto é, aquela cujas "formas sociais digitais articulam suas arquiteturas através do diálogo e do compartilhamento de conteúdo" (DI FELICE, 2013, p. 58). Essa é a fase da Web que cria as possibilidades de escrita coletiva, aprendizagem e colaboração na e em rede, diferente da primeira fase que era, principalmente, para a leitura de informações (LÉVY, 2010, p. 52).

E foi, também, a partir da Web 2.0 que os movimentos sociais em rede ganharam visibilidade. Segundo Castells, esses movimentos possuem algumas características essenciais: são conectados em rede múltiplas formas; se tornam um movimento ao ocupar o espaço urbano; ${ }^{3}$ são simultaneamente locais e globais; são espontâneos em sua origem e geralmente desencadeados por uma centelha de indiginação; são virais, em razão da possibilidade de ver e ouvir protestos de diferentes culturas e contextos distantes, o que inspira o desejo de mudança; são movimentos sem liderança, autogovernados pelos participantes, principalmente pela experiência com a política instituída que inspira desconfiança; são profundamente autorreflexivos; não são violentos; raramente são programáticos, e são muito políticos num sentido fundamental, pois visam a utopia da autonomia do sujeito em relação às instituições da sociedade (CASTELLS, 2013, p. 160-163).

Massimo Di Felice denomina os movimentos sociais em rede de net-ativismo e afirma que eles possuem três fases distintas. A primeira é caracterizada pela rede centralizada e está ligada ao advento da internet a partir das redes de computadores que possibilitou a divulgação e o compartilhamento de informações entre todos os internautas. O principal exemplo é a $A s-$ sociation pour la communication progressiste (APC), criada em 1988 e que reunia, no período, mais de seis mil membros de organizações diferentes, do pacifismo à ecologia e direitos humanos (DI FELICE, 2013).

A segunda fase é a marcada pela rede descentralizada, em razão da "experimentação das primeiras formas de conflitualidades sociais que pela internet deslocam a ação social para uma espacialidade informático-planetária". 0 exemplo que caracteriza essa fase é o movimento zapatista (DI FELICE, 2013), que é inspirado nos ideais de Emiliano Zapata e nasceu nas selvas de Chiapas em $1^{\circ}$ de janeiro de 1994 , com o objetivo de lutar pelos direitos do povo mexicano, especialmente os indígenas (MORAES, 2007, p. 8-9).

3. O espaço do movimento é sempre feito de uma interação do espaço dos fluxos na internet e nas redes de comunicação sem fio com o espaço dos lugares ocupados e dos prédios simbólicos visados em seus atos de protesto. E esse espaço é definido como espaço da autonomia - híbrido de cibernético e espaço urbano (CASTELLS, 2013, p. 160). 
E a terceira fase, conhecida como rede distribuída, ganhou espaço a partir da Web 2.0 e do social Network e se exprime por meio de redes eficazes de ativismo e colaboração, em que a informação é "horizontal, dialógica e redundante" e onde cada nó tem "igual importância e poder de interdependência”. É marcada pela "passagem da forma de conflitualidade informativa-mediática para formas reticulares autônomas e colaborativas de ativismo" (DI FELICE, 2013, p. 55-57).

Entretanto, preparar os sujeitos para se tornarem atores sociais e políticos não é um processo simples. É preciso incitar a participação em diversos espaços, desde mobilizações locais até o empoderamento por meio dos fóruns e debates disponíveis on-line e a garantia de uma representação ativa nas conferências nacionais e globais que são de iniciativa do governo em parceria com a sociedade civil organizada (SCHERER-WARREM, 2006, p.123), como o Fórum Social Mundial, que é amplamente divulgado e possui extensa participação social, com debates acerca de temas que movimentam lutas em prol dos direitos humanos.

Porém, ainda há um grande limitador nas sociedades para que o ativismo digital possa de estender para toda a população: as desigualdades econômicas e sociais que impossibilitam o acesso universal e criam grupos de excluídos digitais. De acordo com os dados da pesquisa TIC domicílios ${ }^{4}$ desenvolvida pelo Comitê Gestor da Internet no Brasil (CGI.br), apenas $49 \%$ da população brasileira com 10 anos ou mais é usuária da internet, fator que é acentuado pelas desigualdades regionais (regiões Sul e Sudeste com 55 e $54 \%$, regiões Norte e Nordeste com 30 e $31 \%$ e região centro-oeste com 46\%), e desigualdades econômicas (classe A com $97 \%$ e classes D e E somente $6 \%$ com acesso) (PESQUISA..., 2013).

Cicília Peruzzo (2005, p. 269-270) entende que o acesso é desigual e "beneficia as classes ricas e médias na proporção da desigualdade econômica existente dentro dos países e entre países" e, gerando

\footnotetext{
4. Pesquisa com dados de 2012
}

novas categorias sociais, como os conectados e não conectados, incluídos e excluídos do acesso às redes digitais. $E$ isso acaba criando "novos instrumentos para hegemonias antidemocráticas e elitizadas" (BRITO, 2011, p. 119-120), se afastando do ideal democrático de acesso às informações e conhecimentos universais com transparência, solidariedade e participação de todos os cidadãos.

Para Castells, os países que não estão equipados com plataforma digital têm muito menos probabilidade de passar por movimentos populares em prol da democracia, porque "as redes da internet e de telefonia celular não são apenas ferramentas, mas formas organizacionais, expressões culturais e plataformas específicas para a autonomia política" (CASTELLS, 2013, p. 82-84).

Para Giuseppa Spenillo, só é possível alcançar uma real democracia se os meios para produzir comunicação estiverem ao alcance de todos.

\begin{abstract}
Para que as comunidades populares possam rever o lugar de receptores que thes tem sido conferido em nossa sociedade e, assim, chegarmos a uma condição de real democracia, em que os elementos necessários para produzir comunicação (e não só consumi-la) estejam realmente a disposição de todos, é preciso empenho dos comunicadores para levar às camadas populares o arsenal de recursos tecnológicos a serviço da comunicação e, mais do que isto, trabalhar em prol de encontrar e fazer serem usados os recursos comunicacionais locais, variados e ricos. (SPENILLO, 2004, p. 251).
\end{abstract}

Contudo, o problema do acesso físico à tecnologia não é a única barreira para a participação social e política na rede. A questão relaciona-se, também, com a "formação discursiva da vontade", pois para que um debate público alcance proporções capazes de incitar mudanças, é preciso um alto nível de interesse político e não apenas ativismo político. Daí a importância em se investir em uma educação tecnológica capaz de mobilizar a parcela da sociedade com apatia política (MAIA, 2008, p. 285).

O principal papel dos novos atores políticos e sociais que emergiram e emergem a partir da rede 
é garantir o compartilhamento e o valor público e cívico ${ }^{5}$ do que é produzido no ciberespaço, pois são esses valores que possibilitam benefícios para a sociedade como um todo e é a partir deles que se desenvolvem as lutas sociais, já que trabalham com a tensão existente entre a liberdade individual e o valor social. Porém, é importante ressaltar que os valores, pessoal e comum ${ }^{6}$, não devem desaparecer, pois a sociedade, também, se beneficia com eles. 0 que é necessário é o fortalecimento dos valores público e cívico, tendo em vista o papel que desempenham na rede (SHIRKY, 2011, p. 153-157).

Isso, porque a principal fonte de significado é o processo de comunicação socializada. "Os seres humanos criam significado interagindo com seu ambiente e com as redes sociais" (CASTELLS, 2013, p. 11-21). É daí que nasce a capacidade dos atores sociais de desafiarem o poder embutido nas instituições da sociedade. Os movimentos sociais exercem o contrapoder ao construírem-se mediante um "processo de comunicação autônoma, livre do controle dos que detêm o poder institucional" (CASTELLS, 2013, p.1-21).

É nessa perspectiva que se denota a importância desses novos atores sociais que estão emergindo por meio das redes. A resistência que surge - aos poderes hegemônicos e o desejo de mudança, instiga os indivíduos em busca de uma sociedade mais igualitária e com garantia dos direitos e liberdades. É o fio da indignação que Castells alega que move as pessoas e permite desenvolver a esperança por algo melhor.

5. O compartilhamento público é aquele que permite que as pessoas se juntem à vontade ao grupo e os resultados serão disponibilizados mesmo àquelas pessoas que não são participantes. Exemplo: projeto Apache. Já o valor cívico é igual ao público no sentido de ser aberto, mas o seu objetivo é melhorar a sociedade. Um exemplo é a Associação de mulheres livres, avançadas e frequentadoras de bares, de Nisha Susan, que foi criada para aumentar a liberdade de todas as mulheres indianas e não só das integrantes (SHIRKY 2011, p. 155-156).

6. 0 valor pessoal é o tipo de valor que recebemos por estar ativos em vez de passivos, por ser criativos em vez de consumistas. É o tipo de compartilhamento mais simples, em que tanto os participantes como beneficiários estão agindo de forma individual, mas recebem valor pessoal advindo da presença uns dos outros. Já o valor comum é mais complicado, pois requer mais interação que o valor pessoal; porém, permanece dentro do círculo de participantes. É o caso dos grupos de Meetup.com para depressão pós-parto que criam valor apenas para seus membros (SHIRKY, 2011, p. 153-155).

\section{RESULTADOS E CONCLUSÃO}

A partir da pesquisa apresentada, denota-se que os movimentos sociais, em prol da cidadania, percorreram um longo caminho no nosso país, tendo início ainda no período do Brasil Colônia, quando os agrupamentos eram formados em prol da independência. Contudo, foram sendo alterados conforme a realidade sociológica de cada período, encontrando um espaço maior de deliberação a partir de 1970, especialmente em razão do processo de redemocratização vivenciado pelo Brasil no período conturbado da ditadura militar.

E esses novos movimentos sociais que emergiram nessa época e detinham um caráter mais heterogêneo que os movimentos anteriores, foram reforçados com o advento da internet, principalmente da Web 2.0, que possibilitou uma alteração no processo comunicativo e uma abertura das informações, com acesso instantâneo e sem limites territoriais para o alcance.

A partir dessas novas concepções que os atores políticos e sociais emergem, buscando um espaço público aberto de discussão e deliberação, em prol da garantia do exercício da cidadania e da efetivação dos direitos humanos e fundamentais.

Assim, a partir desse contexto, denota-se a necessidade de pensar o papel do novo ator político e social que emergiu com as redes e luta em prol de melhores condições de vida, oferecendo resistência aos poderes institucionais tradicionais. 0 ativismo precisa estar alicerçado aos valores públicos e cívicos, como forma de impulsionar o exercício dos direitos individuais, políticos e sociais, reforçando o papel do Estado Democrático de Direito.

\section{REFERÊNCIAS}

ARISTÓTELES. Política. Tradução de Mário da Gama Cury. Brasília: Universidade de Brasília, 1985. 
BRITO, José Augusto Pereira. Cibercidadania: a virtualização na comunicação pública contemporânea. Revista Organicom. v.3 n.4, 2011. Disponível em: <scholar.google.com.br>. Acesso em: fev. 2015.

CASTELLS, Manuel. Redes de indignação e esperança: Movimentos sociais na era da internet. Tradução de Carlos Alberto Medeiros. Rio de Janeiro: Zahar, 2013.

CASTELLS, Manuel. A Galáxia internet: reflexões sobre internet, negócios e sociedade. Tradução de Maria Luiza X. de A. Borges. Rio de Janeiro: Jorge Zahar, 2003.

DI FELICE, Massimo. Ser redes: O formismo digital dos movimentos net-ativistas. Revista Matrizes. Ano 7, n.2. São Paulo, jul./dez. 2013. p.49-71. Disponível em <scholar.google.com.br>. Acesso em: fev. 2015.

GOHN, Maria da Glória. História dos Movimentos e Lutas Sociais: a construção da cidadania dos brasileiros. 2.ed. São Paulo: Loyola, 2001.

HABERMAS, Jürgen. Direito e Democracia: entre facticidade e validade. V.II. Tradução de Flávio Beno Siebeneichler. Rio de Janeiro: Tempo Brasileiro, 1997.

KARNAL, Leandro. Estados Unidos, Liberdade e Cidadania. In: PINSKY, Jaime; PINSKY, Carla Bassanezi (Orgs.). História da cidadania. 2.ed. São Paulo: Contexto, 2003.

LAKATOS, Eva Maria; MARCONI, Marina de Andrade. Fundamentos de metodologia científica. 4.ed. São Paulo: Atlas, 2001.

LEMOS, André; LÉVY, Pierre. 0 futuro da internet: em direção a uma ciberdemocracia. São Paulo: Paulus, 2010.

LUBENOW, Jorge Adriano. Esfera pública e democracia deliberativa em Habermas: modelo teórico e discursos críticos. Kriterion: Revista de filosofia, v.51, n.121. p.227-258. Belo Horizonte, 2010. Disponível em <http://www.scielo.br/scielo.php?pid=S0100-
-512X2010000100012\&script=sci_a rttext\#back32>. Acesso em: fev. 2015.

MACHADO, Jorge Alberto S. Ativismo em rede e conexões identitárias: novas perspectivas para os movimentos sociais. Revista Sociologias. Ano 9, n.18, Porto Alegre, jul./dez. 2007. p.248-285. Disponível em: <scholar.google.com.br>. Acesso em: fev. 2015.

MADEC, Annick; MURARD, Numa. Cidadania e Políticas Sociais. Lisboa: Instituto Piaget, 1998.

MAIA, Rousiley C.M. Democracia e a internet como esfera pública virtual: aproximação às condições de deliberação. In: GOMES, Wilson; MAIA, Rousiley C.M. Comunicação e Democracia: Problemas e Perspectivas. São Paulo: Paulus, 2008.

MORAES, Felipe Machado de. A palavra zapatista: uma revolução mediática como estratégia de comunicação e emancipação social. Revista eletrônica do programa de doutoramento pós-colonialismo e cidadania global, n.2. 2007. Disponível em <http://cabodostrabalhos.ces.uc.pt/n2/documentos/2006_felipe_moraes_a_palavra_zapatista. pdf>. Acesso em: fev. 2015.

OLIVEIRA, Silvio Luiz de. Tratado de metodologia científica: projetos de pesquisas, TGI, TCC, monografias, dissertações e teses. São Paulo: Pioneira, 1997.

PATROCÍNIO, Tomás. Para uma genealogia da cidadania digital. Educação, Formação \& Tecnologias (ISSN 1646-933X), v.1, n.1, 2008. p.47-68. Disponível em <http://ef.educom.pt>. Acesso em: set. 2014.

PEREIRA, Marcus Abílio. Internet e mobilização política - Os movimentos sociais na era digital. Associação Brasileira de pesquisadores em comunicação política. IV Encontro da Cosmopolítica. Universidade do Estado do Rio de Janeiro: 13 a 15 de abril de 2011. Disponível em: <scholar.google.com. br>. Acesso em: set. 2014. 
PERUZZO, Cecília M. K. Internet e Democracia comunicacional: entre os entraves e utopias e o direito à comunicação. In: MARQUES DE MELO, J.; SATHLER, L. Direitos à comunicação na Sociedade da informação. São Bernardo do Campo, São Paulo: Umesp, 2005.

PESQUISA sobre o uso das tecnologias de informação e comunicação no Brasil (Livro Eletrônico): TIC domicílios e empresas 2012. Coordenação executiva e editorial: Alexandre F. Barbosa. Tradução de DB Comunicação (Org.). São Paulo: Comitê Gestor da Internet no Brasil (CGI.br), 2013. Disponível em <www.cgi.br>. Acesso em: set. 2014.

PINSKY, Jaime. Os profetas sociais e o deus da cidadania. In: PINSKY, Jaime; PINSKY, Carla Bassanezi (Orgs.). História da cidadania. 2.ed. São Paulo: Contexto, 2003.

SCHERER-WARREN, Ilse. Das mobilizações às redes de movimentos sociais. Revista Sociedade e Estado. v.21, n.1, jan./abr. Brasília, 2006, p.109-130. Disponível em <scholar.google.com.br>.
SCHNAPPER, Dominique. Os limites da expressão empresa cidadã. In: MORIN, Edgar; PRIGOGINE, Ilya. (Orgs.). A sociedade em busca de valores: para fugir à alternativa entre o cepticismo e o dogmatismo. Lisboa: Instituto Piaget, 1998.

SHIRKY, Clay. A cultura da participação: criatividade e generosidade no mundo conectado. Tradução de Celina Portocarrero. Rio de Janeiro: Zahar, 2011.

SPENILLO, Giuseppa. Comunicação Comunitária e novas tecnologias - por uma formação profissional em busca da cidadania. In: PERUZZO, Cecília M. Krohling. Vozes cidadãs: aspectos teóricos e análises de experiências de comunicação popular e sindical na América Latina. São Paulo: Angellara, 2004.

ZEIFERT, Luiz Paulo. A exclusão social na Grécia Clássica e a postura dos sofistas: repercussões nos processos emancipatórios contemporâneos. ljuí: Unijuí, 2004. 